\title{
The effect of terminal sire breed and slaughter weight on pig production and carcass performance
}

E. Magowan, M.E.E. McCann

Agri-Food and Biosciences Institute, Hillsborough, United KingdomＥmail: elizabeth.magowan@afbini.gov.uk

Introduction Magowan et al. (2007) found that the growth performance of Landrace x Large White (LR x LW) pigs between commercial herds in Northern Ireland varied significantly. Since that time, the use of other breeds in NI has increased greatly. The current study investigated the effect of breed on pig performance and carcass quality of pigs when taken to different slaughter weights.

Materials and methods Over 12 time replicates, a total of 192 LR x LW F1 dams were artificially inseminated with semen from either the Tempo, Pietrain Austrian (PA), Pietrain Belgium (PB) or Landrace (LR) breed. The semen supplier was asked for semen from two of the top performing boars within each breed. The production performance of 240 pigs per breed, over 12 time replicates was compared between weaning and slaughter. All pigs were weighed at weaning (28 days of age) and pigs of the same breed were penned together in groups of 20 from weaning to finish. Each pen was balanced for weight and sex within each replicate. Pigs were weighed and feed intakes were recorded at 10 and 20 weeks of age and finish (target weight of $105 \mathrm{~kg}$ ). Average daily gain (ADG), average daily feed intake (ADFI), feed conversion ratio (FCR) and the coefficient of variation $(\mathrm{CV})$ for weight and growth rate was subsequently calculated. The back fat depth at $\mathrm{P}_{2}$ and hot weight of carcasses were measured 45 minutes after slaughter. Carcass FCR was calculated by dividing the total feed used from weaning to finish by the hot weight of the carcass. Six boars and six gilts within each breed (and balanced for sire) were taken to slaughter weights of either 95,105 or $115 \mathrm{~kg}$. Their back fat depth at $\mathrm{P}_{2}$ and hot weight was measured 45 minutes after slaughter. Analysis of variance was used to test for the effects of breed on pig and carcass performance measurements and the effect of slaughter weight on back fat depth at P2 and kill out percentage

Results Breed had no significant $(\mathrm{P}>0.05)$ effect on pig performance post weaning (4 to 10 weeks of age). However, during the finishing period (10 weeks of age to approximately $105 \mathrm{~kg}$ ) Tempo pigs had the highest ADG, highest ADFI and lowest FCR (Table 1). The CV of 20 week weight and CV for growth rate (10 to 20 weeks of age) were highest in LR pigs (Table 1). LR pigs also had the greatest back fat depth at $\mathrm{P}_{2}$ but a similar kill out $\%$ to Tempo pigs while $\mathrm{PA}$ and $\mathrm{PB}$ pigs had the highest kill out \% (Table 1). Breed had a significant effect on carcass FCR $(\mathrm{P}<0.01$, SED 0.048) with that of the Tempo pigs being best (2.59), that of LR pigs being poorest (2.76) and that of the PA and PB pigs being intermediate (2.64 and 2.68 respectively). When slaughter weights were increased to $115 \mathrm{~kg}$, the back fat depth of all pigs increased significantly (Figure 1). However, at these heavy carcass weights, only LR pigs fell into code 2 (average $14.9 \mathrm{~mm}$ and $15.4 \mathrm{~mm}$ for slaughter weights of 105 and $115 \mathrm{~kg}$ respectively) (Figure 1). Slaughter weight did not affect the kill out percentage of pigs $(\mathrm{P}>0.05)$.

Table 2 Pig performance (10 weeks of age to finish (105kg)) and carcass quality of pigs from different breeds

\begin{tabular}{lllllll}
\hline \hline & LR & PA & PB & Tempo & SED & Sig \\
\hline ADG (g/day) & $804^{\mathrm{a}}$ & $815^{\mathrm{a}}$ & $794^{\mathrm{a}}$ & $888^{\mathrm{b}}$ & 11.6 & $<0.001$ \\
ADFI (g/day) & $2083^{\mathrm{bc}}$ & $2027^{\mathrm{ab}}$ & $2006^{\mathrm{a}}$ & $2119^{\mathrm{c}}$ & 35.6 & $<0.05$ \\
FCR & $2.68^{\mathrm{c}}$ & $2.52^{\mathrm{ab}}$ & $2.59^{\mathrm{bc}}$ & $2.44^{\mathrm{a}}$ & 0.047 & $<0.001$ \\
Back fat depth at P2 (mm) & $13.9^{\mathrm{b}}$ & $12.8^{\mathrm{a}}$ & $12.6^{\mathrm{a}}$ & $12.9^{\mathrm{a}}$ & 0.23 & $<0.001$ \\
Kill Out \% & $75.8^{\mathrm{a}}$ & $77.4^{\mathrm{b}}$ & $77.0^{\mathrm{b}}$ & $76.1^{\mathrm{a}}$ & 0.28 & $<0.001$ \\
CV 20 week weight & $0.12^{\mathrm{b}}$ & $0.10^{\mathrm{a}}$ & $0.11^{\mathrm{ab}}$ & $0.09^{\mathrm{a}}$ & 0.011 & $<0.05$ \\
CV ADG 10-20 weeks of age & $0.17^{\mathrm{b}}$ & $0.12^{\mathrm{a}}$ & $0.14^{\mathrm{ab}}$ & $0.11^{\mathrm{a}}$ & 0.017 & $<0.01$ \\
\hline \hline
\end{tabular}

a,b,c, numbers with the same superscripts are not significantly different $(\mathrm{P}>0.05)$

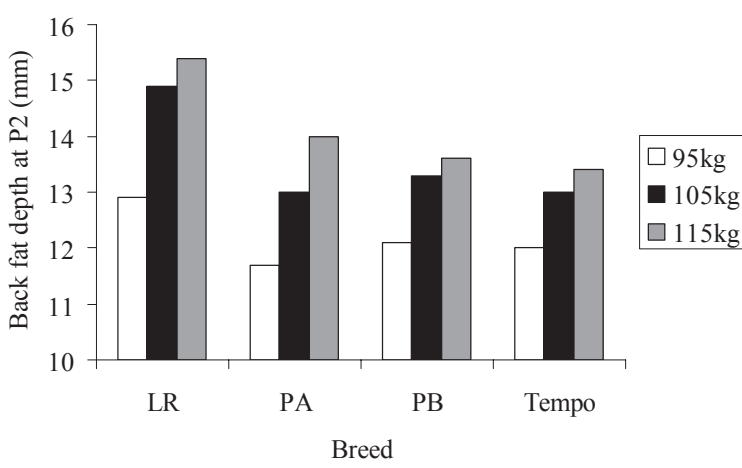

Conclusion. Tempo pigs grew faster and were more efficient than PA, $\mathrm{PB}$ or LR pigs. However, the carcass performance of PA and PB pigs was superior to Tempo and LR pigs. It is likely that the economic value of using Tempo and Pietrain Austrian pigs is similar and greater than that of Landrace pigs. This study highlights the variation in pig performance and carcass quality that can arise from different breeds. When the slaughter weights of pigs were increased, it was found that although back fat depth increased across all genetic sources, only Landrace pigs would have been penalised at the heavier slaughter weights.

Acknowledgements This work was jointly funded by Pig ReGen Ltd

Figure 1 The effect of breed and slaughter weight on back fat depth at $\mathrm{P}_{2}$

\section{References}

Magowan, E., McCann, M.E.E., Beattie, V.E., McCracken, K.J., Henry, W., Smyth. 2007. Animal 1, 1219 - 1226 